\title{
Nanoscale Fracture Morphologies of Soft Magnetic CoFeTaB Amorphous Alloy
}

\author{
J. MišKuF*, K. Csach, A. Juríková, M. Huráková \\ Institute of Experimental Physics SAS, Watsonova 47, 04001 Košice, Slovakia
}

\begin{abstract}
We analyzed the failure characteristics of the bulk metallic glass $\mathrm{Co}_{43} \mathrm{Fe}_{20} \mathrm{Ta}_{5.5} \mathrm{~B}_{31.5}$ (at.\%) deformed by compression and by bending of the ribbons. Under the load the amorphous structure can store high elastic energy. The surface morphology of nanoscale fracture is in accord with the micromechanisms of the failure of the amorphous structure. The fracture surface consists of a smooth mirror cleavage zone and a river pattern zone with nanosized dimples, arranged in lines respecting the periodic corrugation zones, oriented perpendicular to the crack propagation direction. The presence of the failure initiation centers in the ribbon influences the dynamics of crack propagation and also the surface morphology of the fracture.
\end{abstract}

DOI: 10.12693 /APhysPolA.126.96

PACS: 61.43.Dq, 62.25.Mn

\section{Introduction}

Although the mechanical behaviour of bulk metallic glasses (BMGs) has been extensively studied for a number of years, the nature of the deformation mechanisms is still unclear. The main limitation for their application as structural materials is the large brittleness. During the failure processes the material characteristics, especially deformation defects act and influence the final fracture surface morphology [1, 2]. High-strength bulk metallic glasses usually exhibit the brittle behavior at the macroscopic level (like silicate glasses) whereas at the microscopic level they keep the ductile behavior with necking and cavitation of viscous materials in liquid-like zone (obviously observed in metallic glasses) [3].

$\mathrm{Co}_{43} \mathrm{Fe}_{20} \mathrm{Ta}_{5.5} \mathrm{~B}_{31.5}$ bulk glassy alloy has the best glassforming ability among Co-based glassy alloys, and the highest strength (the compressive true strength $\sigma_{f}=$ $5185 \mathrm{MPa}$ ) among all known bulk crystalline and glassy alloys. In addition, the ultrahigh-strength glassy alloys simultaneously exhibited excellent soft magnetic properties, i.e., saturation magnetization of $0.32-0.35 \mathrm{~T}$, low coercive field of $0.7-1.1 \mathrm{Am}^{-1}$, and high effective permeability of $(3.9-4.77) \times 10^{4}$ at $1 \mathrm{kHz}[4]$.

The combination of glassy nature and metallic bonds makes the deformation and fracture mechanisms in bulk metallic glass BMGs remarkably different from either crystalline metals or non-metallic glasses. The plastic deformation of BMGs at room temperature is sustained by cooperative shearing of atomic clusters, termed the shear transformation zones (STZs) [5].

\section{Experimental}

The bulk amorphous alloy with nominal composition of $\mathrm{Co}_{43} \mathrm{Fe}_{20} \mathrm{Ta}_{5.5} \mathrm{~B}_{31.5}$ (at.\%) in the form of cylinders with diameters of $2 \mathrm{~mm}$ produced by an ejection copper mold casting method and ribbons $3 \mathrm{~mm} \times 0.030 \mathrm{~mm}$ were used

\footnotetext{
* corresponding author; e-mail: miskuf@saske.sk
}

for the experiments. During compression tests the cylinder samples break into many fine fragments. Ribbons were tested at bending. The created fracture surfaces were examined using a high resolution scanning electron microscope.

\section{Results and discussion}

The observations of the fracture surface of failed samples in the form of ribbons and bulk cylinders showed simmilarities in micromorphology of the fracture surface. Although the cooling rate during the preparation of bulk and ribbon samples differ by several tens of times, the macroscopic failure is regarded as fragile in the both cases. In the case of samples loaded by bending, on the tension surface side the shear bands act as the initiation of cracks in the mixed mode [6]. The chevron pattern, typical for brittle failure of metallic glasses, is very fine in the observed alloy. Figure 1 demonstrates the crack propagation from free surface with the transition from chevron-like micromorphology to nanoscaled corrugations [7]. As a crack propagates along the sample, the stress and speed of crack propagation increase. The arrow in Fig. 2 indicates the crack propagation direction. With the increase of crack propagation velocity, the size of periodic stripes shows the tendency to decrease from $90 \mathrm{~nm}$ to about $35 \mathrm{~nm}$. The high strength BMGs store a lot of elastic energy under the loading. The cracks initiate at many locations and samples fail into many fragments $[8,9]$.
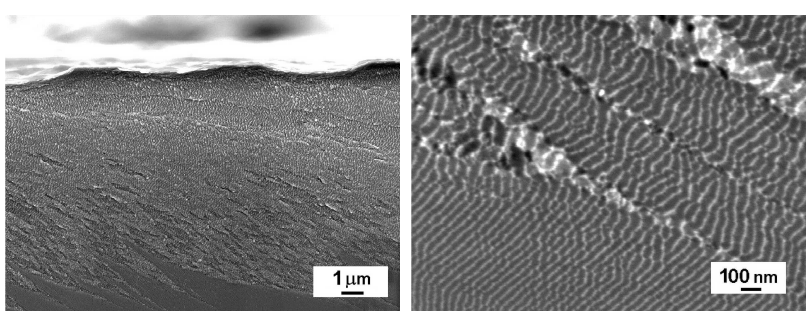

Fig. 1. Fracture surface of ribbon samples after bending - left and a detailed view of the corrugations - right. 


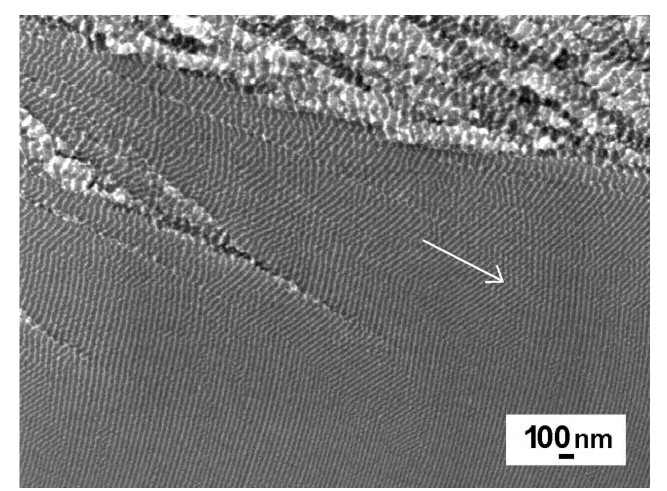

Fig. 2. A detail of corrugations with decreased dimples size along the crack propagation direction marked by the arrow.

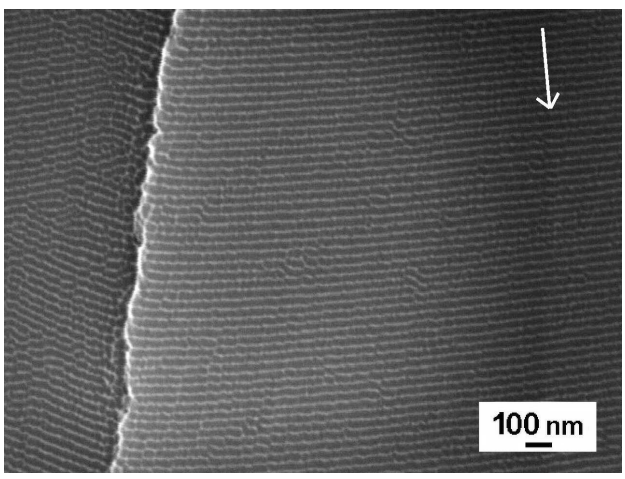

Fig. 3. Typical periodic structure of nanosized dimples.

A detailed view of periodical stripes observed for the majority of fragments is shown in Fig. 3. The period of the corrugation in the case of bulk samples appears to be uniform in the contrary to the fracture surface of ribbons. The corrugation period along the given distances in the crack propagation direction on the fracture surface of the ribbon and bulk samples can be seen in Fig. 4 .

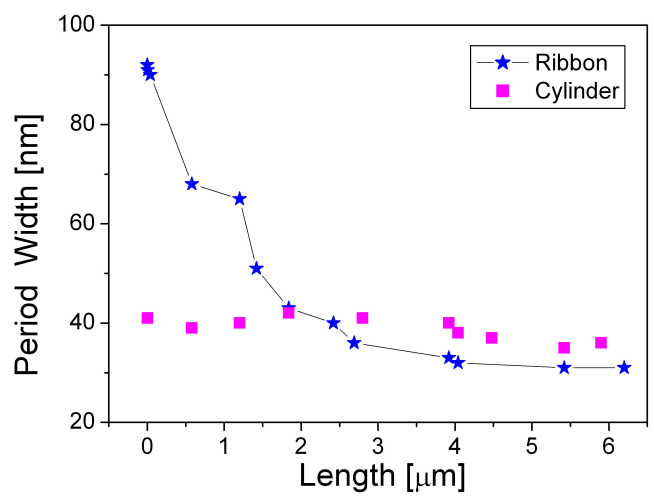

Fig. 4. The wavelength of the nanoscale stripes along the crack propagation.
The meniscus instability process is a widely accepted mechanism for the explanation the ductile failure morphology in amorphous alloys [10]. It is assumed that at a high velocity of the crack tip propagation, the acoustic waves are generated and due to their interferences the periodic free volume collapses and the generation of the voids occurs $[5,11]$. Other possible interpretation of periodic dimple morphology is based on the theoretical model of turbulent conditions of heat generation in front of the crack tip propagation [12]. The fracture surfaces contain the state of frozen-in conditions during the adiabatic shear band generation and failure.

\section{Conclusion}

The morphology on the nanoscaled level is in accord with the micromechanisms of failure in the amorphous alloy structure. The fracture surface consists of a smooth mirror cleavage zone and a river pattern zone with the nanosized dimples, arranged in lines according to the periodic corrugation zones (approximately $40 \mathrm{~nm}$ ), oriented perpendicular to the crack propagation direction. Inside the shear band, the homogeneous nucleation of voids via merging of free volume or STZs in the heated region is present.

\section{Acknowledgments}

This work was supported by the projects Nos. 26220120021 and 26220120033 provided by the European Regional Development Fund, VEGA 0185 and 0045 by the Slovak Academy of Sciences and Slovak Research and Development Agency - contract No. APVV-0171-10

\section{References}

[1] Ch.A.Schuh, T.C. Hufnagel, U. Ramamurty, Acta Mater. 55, 4067 (2007).

[2] V. Ocelík, P. Diko, V. Hajko, J. Miskuf, P. Duhaj, J. Mater. Sci. 22, 2305 (1987).

[3] Z.F. Zhang, F.F. Wu, W. Gao, J. Tan, Z.G. Wang, M. Stoica, J. Das, J. Eckert, B.L. Shen, A. Inoue, Appl. Phys. Lett. 89, 251917 (2006).

[4] B. Shen, A. Inoue, J. Phys.: Condens. Matter 17, 5647 (2005).

[5] X.X. Xia, W.H. Wang, Small 8, 1197 (2012).

[6] R.D. Conner, W.L. Johnson, N.E. Paton, W.D. Nix, J. Appl. Phys. 94, 904 (2003).

[7] G. Wang, D.Q. Zhao, H.Y. Bai, M.X. Pan, A.L. Xia, B.S. Han, X.K. Xi, Y. Wu, W.H. Wang, Phys. Rev. Lett. 98, 235501 (2007).

[8] J.T. Fan, Z.F. Zhang, S.X. Mao, B.L. Shen, A.Inoue, Intermetallics 17, 445 (2009).

[9] W.Z. Liang, X.Y. Mao, L.Z. Wu, H.J. Yu, L. Zhang, J. Mater. Sci. 44, 2016 (2009).

[10] Y.T. Wang, X.K. Xi, G. Wang, X.X. Xia, W.H. Wang, J. Appl. Phys. 106, 113528 (2009).

[11] L.F. Liu, H.A. Zhang, H.Q. Li, G.Y. Zhang, Scripta Mater. 60, 795 (2009).

[12] X. Teng, T. Wierzbicki, H. Couque, Mechanics of Mater. 39, 107 (2007). 